\title{
Os Rituais nos Balneários do Noroeste da Península Ibérica
}

\author{
Silvana Trombetta*
}

\begin{abstract}
TROMBETTA, S. Os Rituais nos Balneários do Noroeste da Península Ibérica. $R$. Museu Arq. Etn., 32: 96-107, 2019.
\end{abstract}

Resumo: Os balneários existentes na região Cantábrica e no Entre-Douro-eMinho têm sido objeto de pesquisas acadêmicas que visam detectar os usos destas construções monumentais bem como os rituais que abrigavam. As construções pétreas existentes na região Cantábrica são aparentemente mais antigas (século IV ou III a.C.), embora haja controvérsias sobre sua cronologia. Além disso, situavam-se junto à porta de entrada dos castros em contraposição às existentes na região do Entre-Douro-e-Minho, implantadas longe dos assentamentos e cujas construções em pedra teriam sido realizadas entre os séculos I a.C - I d.C. Não obstante as significativas diferenças, haveria em ambas banhos rituais interligados ao papel do guerreiro na sociedade galaica, nos quais o calor, a água, a terra e o ar seriam elementos atuantes no processo de regeneração do combatente após a batalha ou no processo de iniciação do guerreiro em sua função bélica.

Palavras-chave: Balneários; Rituais; Cultura Castreja; Guerreiro.

\begin{abstract}
rqueologicamente, a região noroeste de Portugal possui características bastante peculiares, sendo os povos que nela habitavam denominados castrejos ou galaicos. Os traços distintivos desta cultura (cujos vestígios arqueológicos remontam ao Bronze Final) são o habitat em locais elevados e próximos aos recursos naturais, as cabanas circulares construídas com pedra e a presença de balneários (Fig. 1). Este último elemento revela-se particularmente intrigante visto que há poucos edifícios semelhantes em outras regiões da Hispânia no período que antecede a presença romana. ${ }^{1}$
\end{abstract}

${ }^{*}$ ) Mestre e Doutora em Arqueologia pelo MAE/USP. Pesquisadora Associada do Laboratório de Arqueologia Romana Provincial, LARP-MAE/USP <siltrom@yahoo.com.br>

(1) Fora da região noroeste, são conhecidas as saunas de Ulaca (Ávila, século IV-II a.C.), Collado del Freillo (Ávila, século II-I a.C.),
Historicamente, no decorrer do século XIX até meados do XX, a hipótese mais usual era a de que tais construções seriam fornos cre-

\footnotetext{
Tiermes (Soria, século I d.C.), Arcóbriga (Zaragoza. Haveria no local uma sauna "celta" de datação incerta e uma terma do período romano - século I-III d.C.), Bílbilis (Zaragoza, século I-II d.C.), Azaila (Teruel, século I-II d.C.), e Segóbriga (Castile-La Mancha, século I d.C.). A sauna de Ulaca e a sauna "celta" de Arcóbriga destacam-se por terem sido construídas num período pré-romano, tais quais as saunas encontradas no noroeste da Península Ibérica. Em ambas, a construção do edifício foi feita em parte através da escavação de uma grande rocha granítica e possuem os ambientes comumente encontrados nas saunas do noroeste: na sauna de Ulaca há uma antecâmera, uma câmera e um forno e na sauna de Arcobriga além destes ambientes há também a presença do átrio. É interessante observar que tanto em Ulaca quanto em Arcóbriga existem altares sacrificiais talhados em rochas nos quais se observam canaletas que provavelmente destinavam-se a recolher o sangue vertido do animal (ou, talvez, do ser humano) sacrificado. Infelizmente, não é possivivel saber ser haveria uma correlação entre os ritos existentes nas saunas e o altar sacrificial.
} 


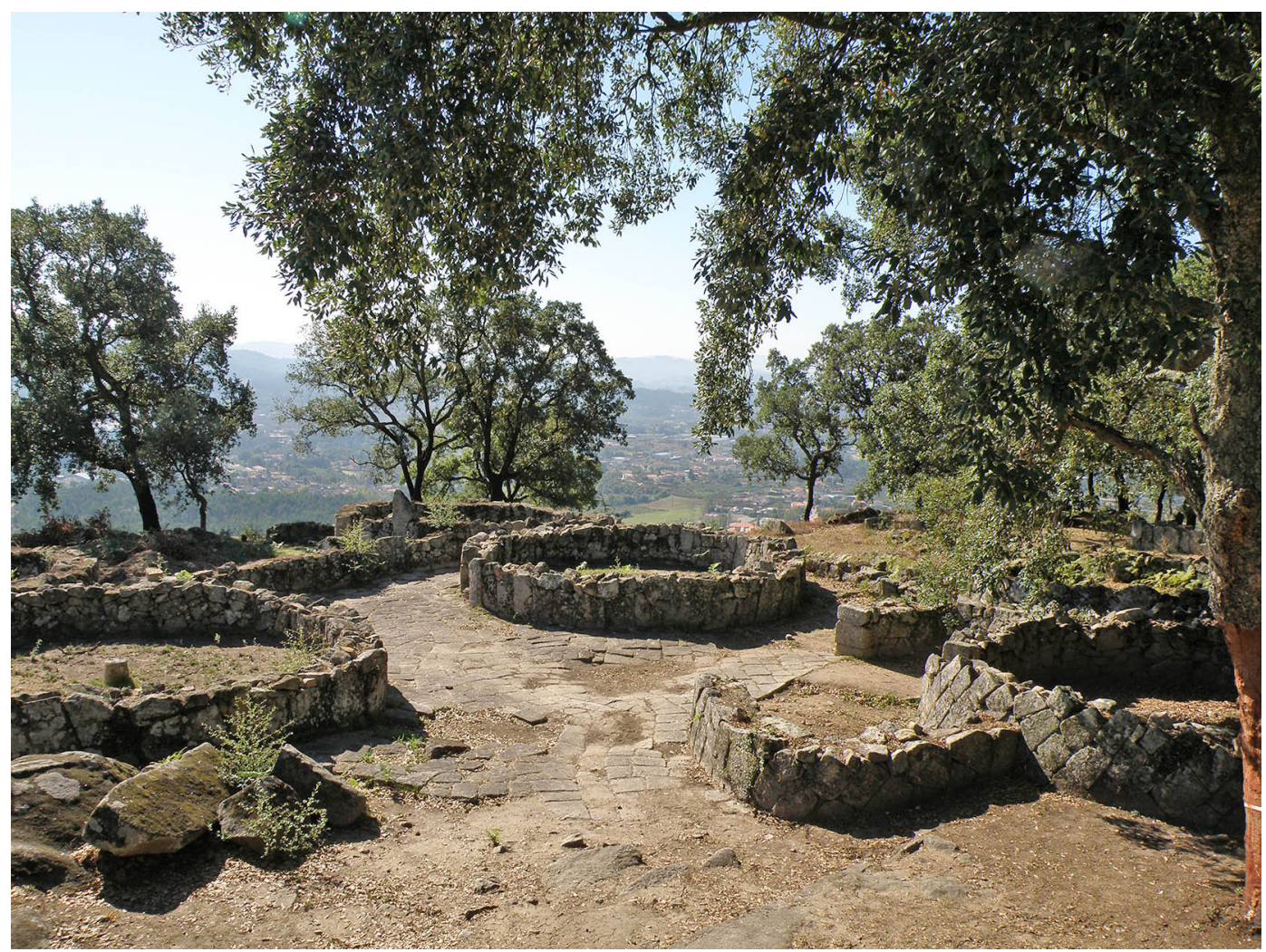

Fig. 1. Citânia de Briteiros - Casas circulares.

Fonte: Taricha Rivularis - Own work, CC BY-SA 3.0, https://commons.wikimedia.org/w/index.php?curid=5931968

matórios, devido à presença de pedras carbonizadas em seu interior e de vestígios de traços deixados pelo fogo na parte interna das paredes (Almagro-Gorbea \& Sanchís 1993:181). A associação desses monumentos com estruturas mortuárias foi frequente devido à falta de enterramentos bem definidos no noroeste da Península Ibérica, pois diferentemente de outros povos (como os celtiberos na região da Meseta) não foram encontrados sepultamentos em urnas cinerárias dispostas num local separado do castro. Segundo Silva (2007) houve entre os castrejos supostos enterramentos infantis em urnas no interior das cabanas entre os anos de 500-200 a.C. ou em cistas de pedra próximas do espaço familiar (136 a.C - 100 d.C.), embora isto não fosse um ato recorrente nos castros. Sopeña (2005), ao descrever as práticas funerárias dos celtiberos, discorre sobre a exposição dos corpos ao ar livre para serem devorados por aves necrófogas e ao analisar os ritos presentes nas Ilhas Britânicas cita a existência de plataformas sobre as águas, de modo que essas transportariam o corpo do defunto para o Outro Mundo. ${ }^{2}$ Assim, o exame de cultos de outras localidades pode esclarecer a exiguidade dos achados funerários no noroeste ibérico na medida em que ritos semelhantes podem ter ocorrido na região. Seguindo este mesmo raciocínio, o arqueólogo Quintela (2016) propõe a hipótese de que no noroeste existiriam as

(2) Para Sopeña (2005:381), o conjunto de grandes pedras justapostas encontradas perto do oppidum de Numância (Soria) seriam plataformas destinadas à exposição dos cadáveres para serem devorados por corvos e abutres (de modo a levar ao céu a alma do defunto). Embora fontes textuais como a de Sílio Itálico (Punica III, 340-343) correlacionem este tipo de culto mortuário com indivíduos pertencentes à elite guerreira, o fato de haver poucos vestígios fúnebres no noroeste, leva à suposição de que nesta região este tipo de rito poderia não ser restrito à camada social mais elevada da população. O mesmo pode ser dito com relação à exposição dos corpos em plataformas de madeira sobre as águas. 
Os Rituais nos Balneários do Noroeste da Península Ibérica R. Museu Arq. Etn., São Paulo, n. 32: 96-107, 2019.

denominadas "torres do silêncio", ${ }^{3}$ estruturas elevadas nas quais o cadáver seria acomodado de modo a decompor sem contaminar o solo e demais elementos naturais circundantes. Não obstante, atualmente nenhuma dessas teorias sobre a questão mortuária no noroeste da Península Ibérica no período que precede a presença romana é conclusiva.

Nos séculos que antecederam nossa época, portanto, a associação entre os edifícios (hoje caracterizados como termais) e a prática ritual pautava-se pela busca de uma explicação plausível sobre ritos funerários nos quais haveria a incineração dos corpos e a subsequente deposição nas águas. Isto elucidaria a ausência de urnas cinerárias e enterramentos no noroeste da Hispânia. No entanto, a falta de ossos calcinados nestas edificações não permitiu avalizar seu uso como funerário, levando à procura de outras interpretações que fundamentassem a construção desses monumentos (Fig. 2). No ano de 1955, os estudos dos arqueólogos Manoel Chamoso e Francisco Conde Valvis postularam que tais construções eram balneários, o que justificaria "seu caráter subterrâneo de modo a salvaguardar seu calor....e uma funcionalidade ligada à presença da água" (Almagro-Gorbea \& Sanchís 1993:182). Embora, em 1968, o arqueólogo Garcia y Bellido tenha novamente argumentado que as construções poderiam estar relacionadas ao aspecto funerário, possuindo a água um caráter lustral de purificação dos restos mortais

(3) O autor faz uma correlação com o Mazdeísmo (também denominado Zoroastrismo), segundo o qual o nascimento dos seres humanos seria resultante de uma diferente combinação de elementos, sendo que na hora da morte haveria técnicas para o tratamento do cadáver (que não deveria ser sepultado na terra ou cremado pela ação do fogo) de modo a evitar a poluição do mundo. Isto levou à construção das Torres do Silêncio, nas quais a carne do falecido era decomposta pela ação dos agentes naturais em conjunção com a atuação de aves necrófagas. Para Quintela (2016:123), a analogia entre esta concepção religiosa presente entre os persas e as tradições celtas pode ser vista nos relatos medievais sobre o Adão Octopartido, formado pela confluência de oito elementos (terra, oceano, sol, vento, nuvem, pedra, Alma Sagrada, Luz do Mundo) e no relato irlandês, no qual Adão é formado a partir de três elementos: suor da água, calor do fogo e respiração do ar. Haveria, para o autor, uma relação entre os elementos naturais que constituem o ser humano e que o desagregam na hora da morte.

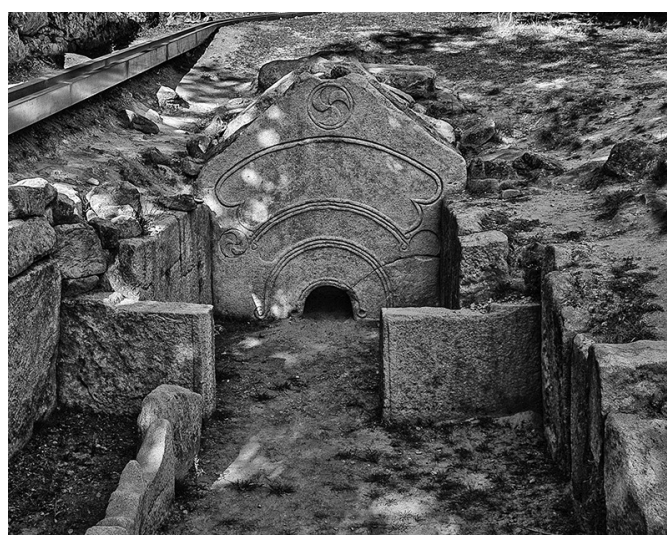

Fig. 2. Balneário Castrejo da Citânia de Briteiros. Fonte: Turismo En Portugal - Pedra_Formosa_Briteiros, CC BY 2.0, httpscommons.wikimedia.orgwindex. phpcurid $=31666900$

e que para o pesquisador espanhol Francisco Jordá a plataforma existente junto à sauna no Castro de Coaña (Villacondide, Coaña) estaria associada com uma divindade ligada às águas, os estudos das décadas ulteriores reafirmaram o uso dos edifícios enquanto termas.

Os dados obtidos na Citânia de Sanfins (Paços de Ferreira) e no denominado Monumento de Santa Maria de Galegos (balneário da Idade do Ferro, situado na área intramuros de um castro de pequenas dimensões implantado num dos sopés do Monte do Facho, perto da Citânia de Roriz em Santo Tirso) permitiram que o arqueólogo português Armando Ferreira da Silva confirmasse a "função de sauna para estes edifícios, baseando-se na localização próxima a cursos d'água, seu caráter subterrâneo para manter o calor, a presença do forno para favorecer a combustão, a descoberta de locais com traços de queima devido à vaporização ou à existência de tanques para os banhos de água fria. Consequentemente, considera estas construções complexos termais que correlaciona com a conhecida passagem de Estrabão $(3,3,6),{ }^{4}$ assinalando que seu uso utilitário não diminui um possível caráter religioso associado à prática do banho, como denuncia o

(4) Segundo esse trecho do relato de Estrabão (Geografia, 3, 3,6 ), "alguns lusitanos que habitam junto ao rio Douro vivem como espartanos, ungindo-se duas vezes com óleo e banhandose com suor obtido por pedras aquecidas, banhando-se em água fria”. 
topônimo "Águas Santas" de um destes monumentos" (Almagro-Gorbea \& Sanchís 1993:183).

Embora atualmente os pesquisadores concordem quanto ao uso desses edifícios como saunas, as conotações que os mesmos adquirem correlacionam-se aos aspectos culturais e ideológicos das populações castrejas, os quais embora possuam similaridades, não são idênticos. É o que se observa na análise dos balneários existentes na região do Entre-Douro-e-Minho em comparação com os da região Cantábrica.

Segundo Quintela (2016:110), há no noroeste da Península Ibérica vinte e seis balneários, sendo que onze situam-se na região Cantábrica e os outros quinze entre os cursos do rio Douro e Minho (Fig. 3). Embora haja aspectos semelhantes entre as saunas de ambas as regiões, há diferenças relativas à cronologia e ao local no qual tais edifícios foram implantados.

Examinando a arquitetura interna das saunas, geralmente as mesmas dividem-se em quatro ambientes (átrio, antecâmera, câmera e forno) ou três (quando excetua-se o átrio) (Fig. 4). Cabe lembrar que o arqueólogo espanhol Quintela adverte para o fato de que as pesquisas comumente buscam padrões que têm por base as saunas do Noroeste e que a descoberta da sauna de Monte Ornedo (Cantábria), que possui nove ambientes, revela que há edifícios que fogem às tipologias pré-estabelecidas. Não obstante tais observações estejam corretas, nos deteremos na averiguação dos ambientes com padrões arquitetônicos semelhantes com o propósito de compreender a simbologia que cerca a implantação e utilização desses edifícios, marcados pela ocorrência de ritos nos quais se afirma o caráter bélico da sociedade castreja e o papel fundamental do guerreiro.

Analisando as saunas de ambas as regiões, nota-se que em relação à cronologia há uma diferença bastante singular entre os balneários da região Cantábrica e os do Noroeste português. Segundo Villa-Valdes (2012:14) e Parcero \& Cobas (2004:46), a cronologia obtida através da datação da cerâmica indígena encontrada nas camadas estratigráficas inferiores da sauna do castro de Chao Samartín (Astúrias) remonta aos séculos IV e II a.C. Ou seja, a construção do edifício com material pétreo seria mais antiga do que as dos balneários encontrados até o presente momento na região do Entre-Douro-e-Minho, cuja cronologia aponta para os séculos I a.C. e I d.C. De acordo com Silva (2001:339-340), os balneários castrejos do noroeste português teriam sido construídos inicialmente com materiais perecíveis e num período posterior com pedra. Tal afirmação encontra suporte em estudos como os de Almagro-Gorbea \& Sanchís (1993), que registram a existência de saunas ${ }^{5} \mathrm{em}$ várias partes do continente europeu e das ilhas britânicas cuja tipologia era variada, existindo as que eram escavadas na própria terra e cobertas com materiais perecíveis como folhas de árvores e peles de animais. Dentro das mesmas eram colocadas pedras candentes sobre as quais aspergia-se água de modo a gerar vapor para os banhos de suor. Geralmente havia ao lado um manancial ou poço com água para que o indivíduo se banhasse após sair da sauna. Este tipo de sauna (bem como suas variantes) seria frequente no mundo indo-europeu e sua presença denotaria raízes correlacionadas às tradições atlânticas que particularmente teriam marcado o noroeste da Península Ibérica visto que o contato por via marítima com os povos desta região ocorreria desde a Idade do Bronze.

No entanto, podemos nos colocar a seguinte questão: por que nos castros portugueses há a presença de cabanas circulares construídas com material pétreo (datadas por radiocarbono) que remontam aos séculos VII e VI a.C. enquanto os balneários seriam construídos inicialmente com materiais perecíveis? Ainda não há respostas definitivas sobre esta questão mas o fato é

(5) Segundo Almagro-Gorbea \& Sanchís (1993:178) os primeiros indícios de utilização de pedras quentes para fazer ferver a água a ser usada em banhos de vapor, documenta-se no III Milênio a.C. em sítios de palafitas da Cultura Horgen (perto do Lago Constança na Suiça). Mesmo que a origem deste tipo de banho ainda seja incerta, achados arqueológicos identificados como fornos ou braseiros abertos têm sido assinalados a partir da Idade do Bronze, tanto no norte como no ocidente da Europa, sendo inclusive relacionados com o florescimento dos cultos aquáticos desenvolvidos desde a Escandinávia até o Mundo Atlântico na Idade do Bronze e do Ferro. Os autores também citam a importância da fonte textual de Sidônio Apolinário (Epistulae, 2, 9, 8-9) que documenta a tradição de banhos a vapor entre os galo-romanos do vale do rio Gardon (região de Languedoc-Roussillon) mesmo em épocas bastante posteriores (V d.C.). 


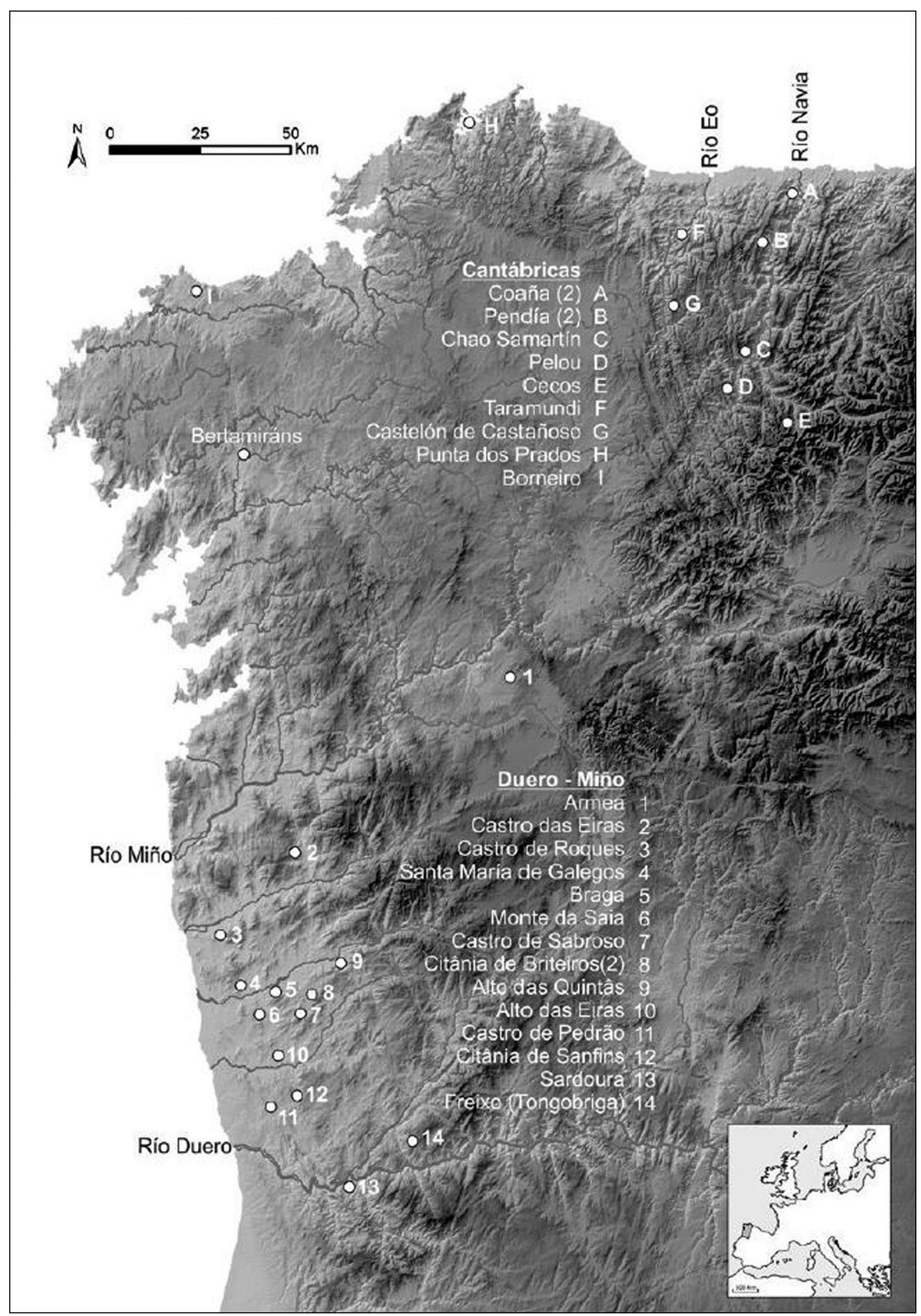

Fig. 3. Mapa com a localização dos balneários no noroeste da Hispânia.

Fonte: Quintela (2016:110) 


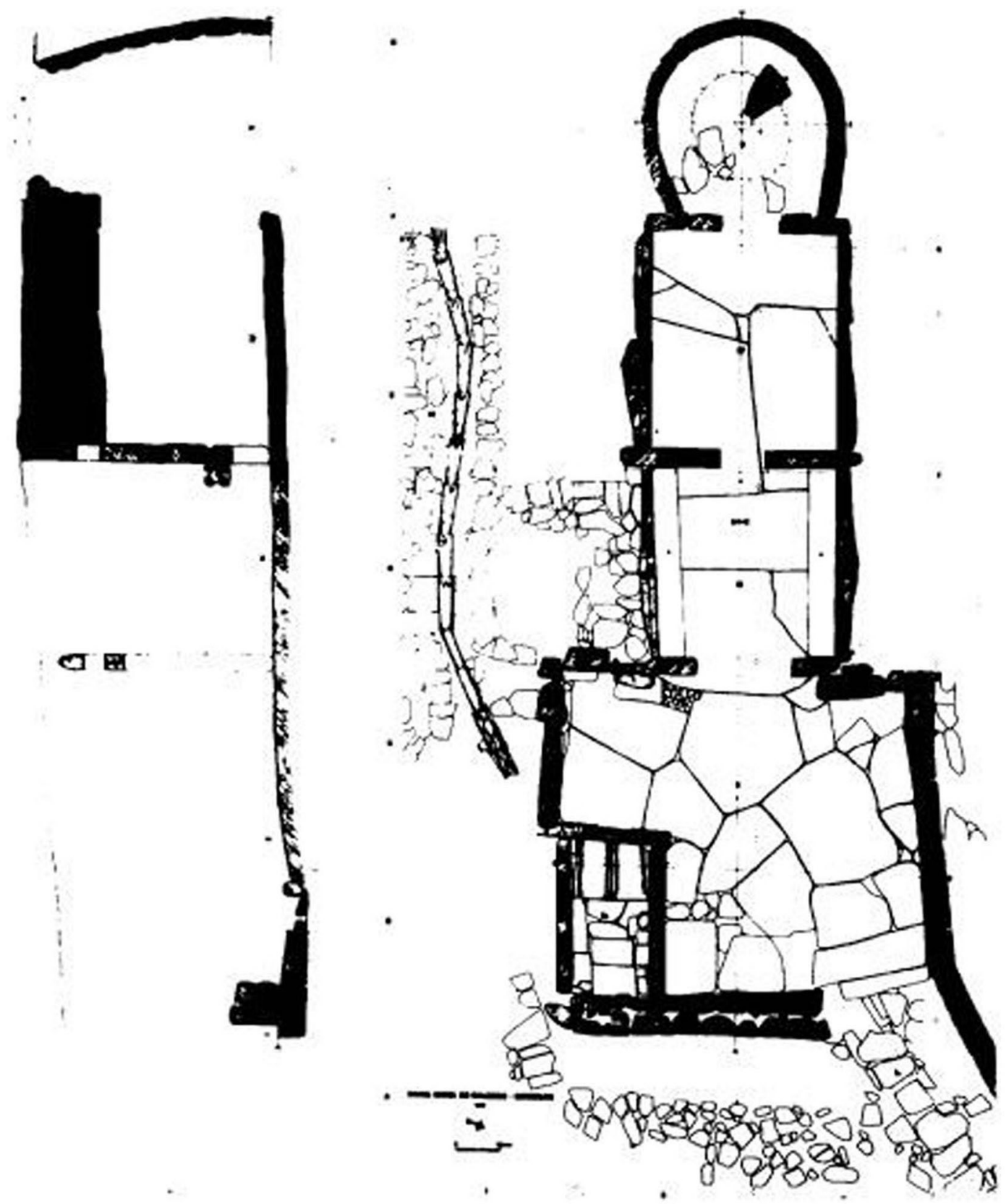

Fig. 4. Planta do balneário de Santa Maria de Galegos (Barcelos), na qual é possível observar de baixo para cima o átrio, a antecâmera, a câmera e o forno (com formato circular). Fonte: Silva (1995:543)

especialmente intrigante visto que o motivo pode estar relacionado a uma necessidade de monumentalização (entre os séculos I a.C. e I d.C.) dos locais em que se realizavam ritos vinculados a uma importante função social exercida pela elite castreja, na qual salienta-se a figura do combatente. Além disso, os locais onde os balneários foram construídos pressupõem que os complexos termais portugueses de material pétreo deveriam ser erigidos em zonas distantes dos recintos amuralhados devido à necessidade de estarem próximos às fontes de água (imprescindíveis ao ato ritualístico relacionado à purificação, o qual será detalhado no decorrer 
do texto), enquanto os cantábricos localizavam-se perto da entrada dos castros e utilizavam pouca água corrente.

É igualmente importante considerar que não há informações sobre os locais onde os supostos balneários portugueses de material perecível teriam sido construídos. Caso a estrutura e o funcionamento fossem similares aos das já citadas saunas indo-europeias, como transcorreu a modificação na paisagem quando a construção passou a ser de material pétreo? Por que no noroeste português haveria uma inter-relação entre fontes de água corrente e balneários de pedra visto que a construção pétrea poderia ser do tipo hipogeu, como ocorre nas saunas cantábricas? Podemos inferir que isto pressupõe variações no tipo de rito ocorrido nas saunas do noroeste.

Com relação aos balneários cantábricos, os mesmos estavam próximos à porta de entrada dos castros o que poderia denotar simbolicamente o rito de purificação do combatente após a batalha antes de adentrar a área habitacional. Os do noroeste português também se relacionam com a purificação do guerreiro, na medida em que se situavam longe dos assentamentos, de modo a criar uma separação entre o local destinado a este tipo de rito e a área residencial. Entretanto, observa-se que na região cantábrica o espaço sagrado da sauna operava em conjunto com os demais locais comunitários e/ou rituais do castro: é, por exemplo, o caso de castro de Chao Samartín (Astúrias). Villa-Valdes (2012) examina no castro a presença de um recinto delimitado por estruturas que isolavam um grande edifício elevado no centro de um planalto e de um pequeno bosque de carvalho. "Tratava-se de um lugar alheio a qualquer atividade doméstica ou de habitação e a totalidade do registro arqueológico sublinha sua função cultual" (Villa-Valdes 2012:33-34). Para o autor, a monumentalização deste lugar sacro (denominado acrópole) ocorreu mediante a artificiosa amplificação de sua visibilidade e apropriação de um símbolo por parte de um grupo ou comunidade em um espaço provavelmente frequentado desde tempos neolíticos. Na região das Astúrias, tais locais comunitários surgiram no início da Segunda Idade do Ferro, integrados aos núcleos populacionais. Assim, a acrópole, a grande cabana de assembleia ${ }^{6}$ (denominada nos castros portugueses "Conselho de Anciãos") e as saunas compunham uma cenografia frequente nesses povoados como lugares próprios para a celebração, a reunião e o cerimonial comunal.

Isto igualmente ocorreria nos castros portugueses, nos quais os balneários com "pedras formosas" teriam se erigido em "locais isolados, sagrados, espaços neutros de congregação para as comunidades castrejas, em torno dos quais se propiciaria a reunião e o acordo de alianças" (Villa-Valdes 2012:35). No entanto, se nos castros portugueses a casa da assembleia (tal qual nos asturianos) encontrava-se dentro do espaço habitacional, o mesmo não sucedia com os balneários. Como já foi dito, ainda não há conclusões definitivas sobre as razões que determinaram tal singularidade embora os pesquisadores coloquem como um dos fatores principais a utilização da água corrente nos balneários portugueses em contraposição às saunas cantábricas que seguem o padrão hipogeu. Assim, o tipo de rito seguiria peculiaridades ainda de todo não decifradas embora se possa afirmar que um aspecto comum diz respeito ao banho ritual relacionado à importância da função bélica na sociedade castreja.

(6) Esses locais eram, na verdade, cabanas de maiores dimensões com a presença de bancos de pedra ao redor da parede interna do recinto. Sua localização muitas vezes era no centro da área habitacional (como no castro português de Monte Mozinho em Penafiel) e sua função é vista por pesquisadores espanhóis e portugueses como um local de reunião para tomada de decisões sobre assuntos comunitários. Segundo Villa-Valdés (2012:41), as habitações geralmente tinham cerca de 12 a 20 metros quadrados enquanto que as casas de assembleia alcançavam normalmente 45 metros quadrados, chegando por vezes a superar 60,70 ou 80 metros quadrados, como nos castros de Coaña, Pendia, Pélou ou Chao Samartín. (7) As denominadas pedras formosas eram blocos de pedra de grandes dimensões, geralmente decorados com motivos cuja simbologia interligava-se à cultura dos povos que habitavam a região. Elas situavam-se no espaço entre a antecâmera e a câmera dos balneários, marcando a passagem de um espaço ao outro através de um orifício de pequenas dimensões situado em sua base. Cabe lembrar que nos castros asturianos, diferentemente dos castros do noroeste português, tais blocos de pedra possuíam pouca ou nenhuma figuração (ainda não há respostas sobre o porquê desta distinção). 
Segundo Almagro-Gorbea \& Sanchís (1993:204), estudos arqueológicos em paralelo com fontes textuais evidenciam que não se tratava de banhos lúdicos nem tampouco medicinais e sim cerimoniais. Do mesmo modo, no aspecto estrutural, a circularidade do forno do balneário não se explicaria somente por sua funcionalidade, mas por aspectos cultuais conectados com funções cosmológicas - celestes e ctônicas. $\mathrm{O}$ próprio fato de que construtivamente a sauna castreja estava semienterrada na terra ou escavada na rocha, revelaria seu caráter ctônico, interligado ao Outro Mundo. A própria decoração das pedras formosas possuía elementos ctônicos ou astrais, tais quais os encontrados nas estelas funerárias castrejas durante o período romano. O elemento água também era dotado de um claro significado ideológico visto que em mais de 50\% destas construções foi registrada a presença de recipientes no átrio para conter água (Coaña, Pendia, Águas Santas, Galegos, Briteiros, Monte da Saia, Sanfins), sendo que em Coaña existia um bloco monolítico de granito de dois metros de largura internamente talhado e vazado de modo a ser um grande contentor de água. Villa-Valdés (2012:37) igualmente enfatiza a importância da água nos ritos que ocorriam nos balneários castrejos próximos ao vale do rio Navia, particularmente nos castros de Pendia e Coaña. No primeiro, foi possível observar num riacho que flui ao pé do castro a presença de uma plataforma de granito submersa (Fig. 5) e no segundo a localização de um pilar granítico a uma distância de $3,8 \mathrm{~km}$ do castro, perto do riacho denominado A Barcúa (embora não submerso). ${ }^{8}$ Ambos os pilares eram similares ao encontrado no citado balneário de Coaña, reforçando, assim, a relação entre a água e o rito de expurgação e regeneração que ocorria nas saunas.

De acordo com Almagro-Gorbea \& Sanchís (1993), os banhos de suor em conjunção com cultos aquáticos eram constantes em todo mundo indo-europeu visto que a água era um

(8) $O$ fato de o pilar não encontrar-se submerso pode ser devido a causas naturais que afetaram o curso do riacho, visto que a água passava somente por uma parte do pilar, escorrendo numa de suas bordas. elemento de comunicação com o Além. Tal contexto sagrado "que rodeia os ambientes aquáticos se faz explicito também durante a Idade do Ferro num documento arqueológico único: o diadema com guerreiros de Moñes (Piloña). As imagens em relevo sobre as finas lâminas de ouro oferecem uma visão excepcional do ideário simbólico dos povos castrejos e seus mitos, da exaltação do guerreiro e o trânsito no mais além, tudo isto tendo o meio aquático como pano de fundo... Neste contexto, o fato mais sugestivo dos pilares submersos em Pendia e Coaña reside no fato de que ambos podem estar assinalando um cenário, um símbolo primordial que encoraja e inspira a liturgia que se desenrola nas saunas castrejas: "as águas primordiais". Aquelas nas quais a imersão provoca o retorno ao pré-formal, com seu duplo sentido de morte e dissolução, mas também de renascimento. As saunas proporcionam a atmosfera ritual necessária para que a água, elemento essencial, suporte e ícone do mito, ative os processos de mudança, destruição e nova criação - de regeneração definitiva - que é a razão última, de todo rito iniciático" (Villa-Valdés 2012:38-39). Assim, para Villa-Valdés (2012), após o retorno da batalha, antes de adentrar o castro, o guerreiro deveria passar por um ritual do qual sairia "renovado" e, portanto, "renascido". Tal qual este autor, Quintela (2016) e Almagro-Gorbea \& Sanchis (1993) igualmente postulam que os balneários possuíam ritos ligados à iniciação do combatente, bem como seu renascimento após a guerra. Arquitetonicamente, esta ideologia estaria expressa nas pedras formosas, visto que a pequena abertura circular em sua base não teria como finalidade apenas conter o calor do ambiente e sim atuar de modo simbólico, significando o nascimento e renascimento do guerreiro. Isto é plenamente observável uma vez que a passagem do interior para o exterior (e vice-versa) só pode ser feita se o indivíduo estiver deitado sobre o solo e, como bem observa Quintela (2016), em balneários castrejos como o de Tongobriga (Marco de Canaveses) a parte exterior junto à pedra formosa é mais rebaixada (Fig. 6), de modo que o indivíduo consegue sair mais facilmente se colocar primeiramente a cabeça, de modo a apoiar depois suas mãos sobre a pedra formosa para facilitar a passagem do restante do seu corpo (que além de suado também era ungido com óleo, de modo a facilitar o ato simbólico de 


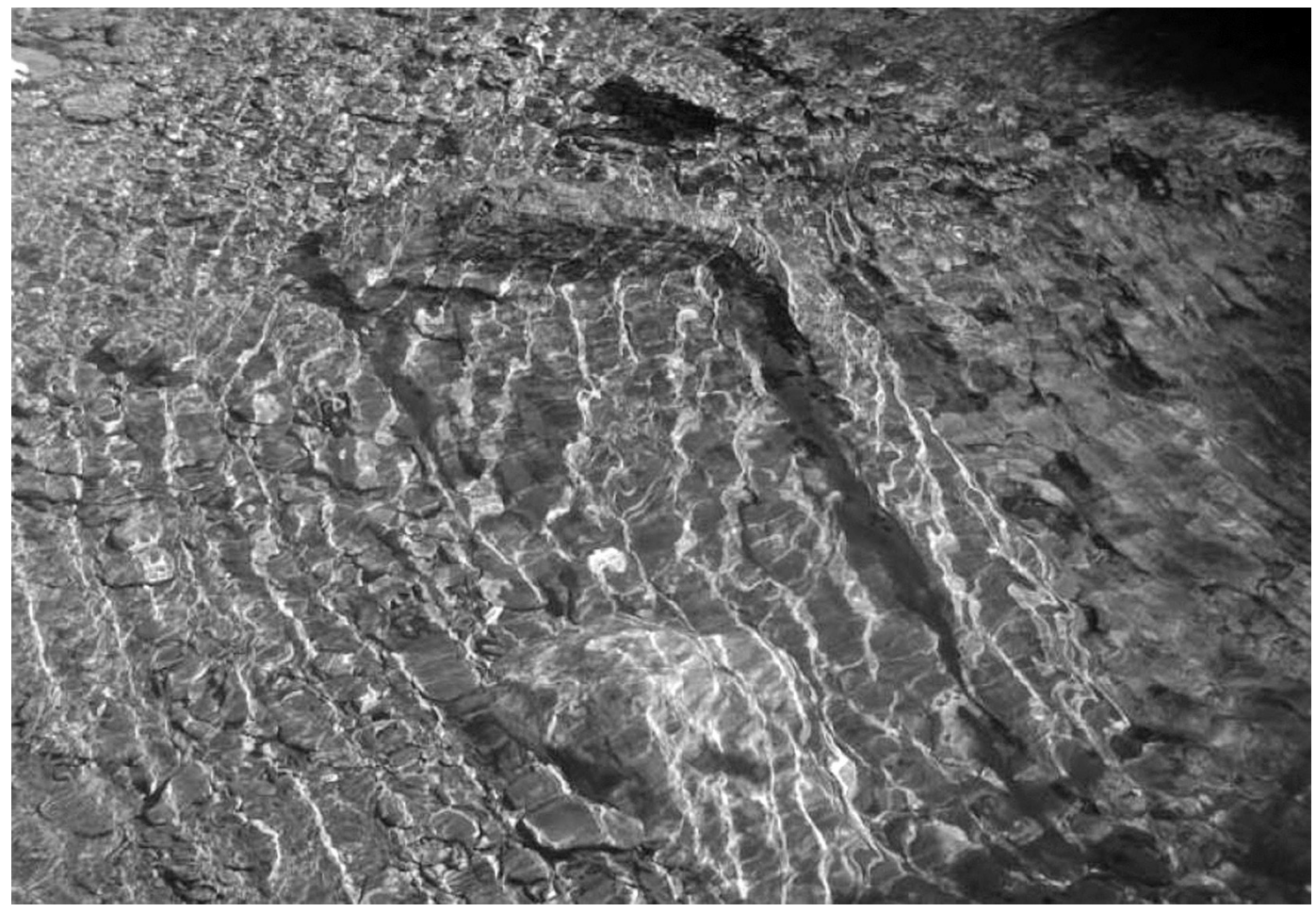

Fig. 5. Bloco granítico submerso no riacho próximo ao castro de Pendia.

Fonte: Villa-Valdés (2012:36)

"escorregar para fora do ventre materno"). Para Quintela (2016:121), a sauna seria, deste modo, uma metáfora pétrea do útero no qual se recria um tipo de gestação, fruto da combinação de água, fogo, ar e terra que culmina com o parto. O fogo, portanto, não teria somente o caráter utilitário de gerar o calor necessário ao funcionamento da sauna. Alegoricamente, ele atuaria como um elemento primordial necessário à evaporação da água sendo, por sua vez, o elemento ar necessário para a combustão do fogo num ambiente circundado pelo elemento terra. Os elementos naturais agregar-se-iam possuindo como finalidade a concepcão do indivíduo.

Tendo em vista os citados ritos existentes nestes edifícios, Villa-Valdés (2012:45) observa que os mesmos "foram depositários de valores transcendentes, diretamente derivados de seu contato com as divindades". E, neste sentido, "a denominação "sauna" resul ta inexata, restritiva e desnecessariamente ambígua pois na realidade nos encontramos ante pequenos santuários urbanos que custodiam os agentes básicos do pensamento religioso, uma porção da divindade que encontra nesses espaços arquitetônicos as condições ótimas para projetar seu potencial purificador e benéfico sobre os homens e a comunidade". Para o autor, a progressiva dessacralização desses espaços somente operou-se no decorrer da conquista romana.

Embora para autores como Quintela (2016:120) não se possa precisar se tais edifícios atuavam exatamente como santuários, sua função simbólica e ideológica é nitidamente expressa pelas características arquitetônicas descritas acima, nas quais se evidencia a comparação da sauna com o útero.

Diante de tudo o que foi exposto, podemos afirmar que tais edifícios estão longe de ter uma função meramente recreativa ou ligada ao asseio. Um uso similar ao que havia nas termas romanas pode ter transcorrido ao longo da contínua presença estrangeira na Península Ibérica, mas isto também é incerto uma vez que em alguns castros, como em Sanfins, houve uma reordenação da malha urbana durante o período romano com a adoção do plano ortogonal, mas o balneário não passou a ser incorporado à área habitacional e não é possível saber se os ritos existentes no local sofreram alterações. 


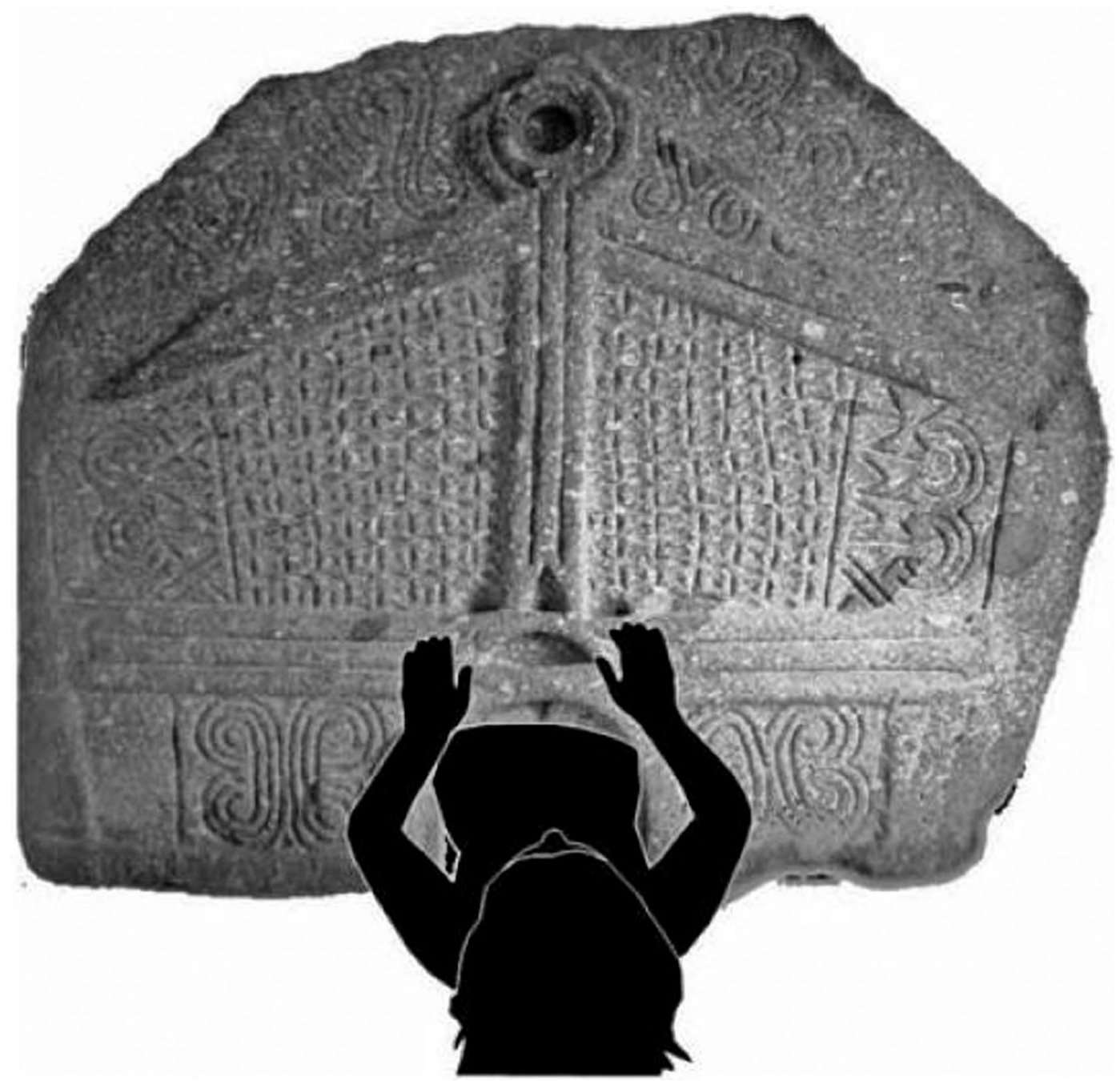

Fig. 6. Pedra Formosa da Citânia de Briteiros com a representação da passagem do guerreiro através do orifício do pilar granítico.

Fonte: Villa-Valdés (2012:41)

Conforme já mencionado, outro ponto ainda não decifrado diz respeito à diferença na localização dos balneários: perto da porta da entrada dos castros na região Cantábrica e distante dos assentamentos na região do Entre-Douro-e-Minho. A presença ou não de água corrente não parece suficiente para explicar o porquê da escolha na implantação dos balneários. Tendo em vista que havia a possibilidade da construção de saunas do tipo hipogeu, a utilização da água corrente parece relacionada a uma diferença ritual. Na região Cantábrica, podemos sugerir que a ênfase esta- ria na integração dos espaços cultuais. Assim, as saunas, as casas de assembleia e os locais de culto (como a "acrópole" do castro de Chao Samartín), deveriam estar próximos, mas, ao mesmo tempo, a sauna deveria estar situada junto à porta de entrada do castro para que o ato de purificação fosse efetivo e se processasse antes do acesso do guerreiro ao espaço habitacional. De modo similar, a importância da imersão em água corrente também é evidente quando se analisa a presença das plataformas graníticas submersas nos riachos próximos aos castros asturianos. Haveria, deste modo, ritos 
que envolveriam imersão em "águas primordiais” com ênfase na regeneração e purificação antes do ingresso no castro.

Nos castros portugueses, pode ter havido uma acentuação do rito de purificação em local afastado (de modo a evitar qualquer mácula nos espaços próximos à área habitacional) ${ }^{9}$ sendo imprescindível o uso de água corrente derivada de fontes ou mananciais. Na medida em que não há achados arqueológicos, até o presente momento, referentes à presença de plataformas graníticas em rios ou córregos próximos aos cas- tros portugueses, o processo de regeneração do indivíduo utilizaria a água fluente dos mananciais de modo a operacionalizar o ato simbólico que envolvia os banhos a vapor e o consequente ato de expurgação.

Não obstante as questões ainda não solucionadas, os balneários presentes na Península Ibérica possuem uma rica simbologia que contempla rituais de iniciação relacionados ideologicamente ao nascimento, renascimento e purificação do guerreiro, contribuindo para o melhor conhecimento da sociedade castreja.

TROMBETTA, S. The Ritual Bath in Northwest Iberian Peninsula. R. Museu Arq. Etn., 32: 96-107, 2019.

Abstract: Thermal baths in Cantabria region and Entre-Douro-eMinho have been the object of academic investigations aiming at establishing the uses of these monumental constructions as well as the rituals linked to them. The stone constructions in Cantabria are probably earlier (IV-III B.C.) than those in Entre-Douro-e-Minho (I BC - I AD.) though there is still much controversy concerning that chronology. Further to this, the Cantabria thermal baths were situated beside the entrance to the castro whilst those of the Entre-Douro-e-Minho in the Northwest of Portugal were located far from the settlement dwellings. Regardless of these significant differences, the rituals that were performed were interconnected with the social role of warriors in Castrejo's society in which heat, water, earth and air were elements actively present in the process of regeneration of combatants after battle or in the ceremonial initiation of warriors in the rites of war.

Keywords: Thermal baths; Rituals; Castrejo's Culture; Warrior.

(9) Neste ponto, diferentemente dos castros asturianos (cujo foco era na integração dos espaços de culto), o aspecto mais relevante seria a separação do balneário da esfera residencial de modo a evitar qualquer contágio ocasionado pelos indivíduos que voltavam da batalha. 


\section{Referências bibliográficas}

\section{Fontes textuais}

Estrabão. 1903. The Geography of Strabo. Hamilton, H.C., Falconer, M.A. (Ed.) George Bell \& Sons, Londres.

Disponível em:

http://www.perseus.tufts.edu/hopper/text?doc=

Perseus:text: 1999.01.0239

Acesso em 10 jun.2018

Silio Itálico - Punica. Walter Coventry Summers, John Percival Postgate (Ed.)

Disponível em:

http://www.perseus.tufts.edu/hopper/text?doc $=$ Per seus\%3Atext\%3A2008.01.0674\%3Abook\% 3D3

Acesso em 10 jun.2018

\section{Obras de apoio}

Almagro, G.; Sanchís, J. R. A. 1993. Saunas y baños iniciáticos en el mundo céltico. Cuadernos de arqueología de la Universidad de Navarra, ISSN 1133-1542, No 1: 177-254.

Disponível em: https://dadun.unav.edu/bitstream/10171/ 14389/1/Almagro-Gorbea-\%C3\%81lvarez Sanch\%C3 \% ADs.pdf

Acesso em: 17 jun 2018

Parcero, C.; Cobas, I. 2004. Iron Age Archaeology in the northwest Iberian Peninsula. e-Keltoi: Journal of Interdisciplinary Celtic Studies (6): 1-72.

Disponível em: https://www4.uwm.edu/celtic/ekeltoi/volumes/vol6/6_1/parcero-cobas_6_1.pdfl. 6 Acesso em 18 jun 2018

Quintela, M. V. G. 2016. Sobre las saunas de la Edad del Hierro en la Península ibérica: novedades, tipologías e interpretaciones. Complutum, Vol. 27 (1):109-130.

Disponível em:

http://revistas.ucm.es/index. php/CMPL/article/view/53219/0

Acesso em 11 jun 2018
Silva, A. C. F. 2007. A cultura castreja no noroeste de Portugal. Câmara Municipal de Paços de Ferreira, Paços de Ferreira.

Silva, A. C. F. 2004. Los pueblos lusitanos-galaicos. In: Almagro-Gorbea et alii (Eds.) Celtas y Vettones. Institución Gran Duque de Ávila. Real Academia de La Historia, Ávila: 334-349. Disponivel em: https://archive.org/details/CELTArqCELTASY VETONESALMAGROEtA-liiLivro Acesso em 10 jun 2018

Silva, A. C. F. 1995. A evolução do habitat castrejo e o processo de proto-urbanização no noroeste de Portugal durante o I Milênio a.C. Revista da Faculdade de Letras. História. N.12: 505-546. Disponível em: http://ler.letras.up.pt/uploads/ ficheiros/2036.pdf Acesso em: 17 de jun 2018

Sopeña, G. 2005. Celtiberian ideologies and religion. e-Keltoi - The Celts in the Iberian Peninsula, Vol.6: 347-410. Disponível em: http://www4.uwm.edu/ celtic/ekeltoi/volumes/vol6/6_7/sopena_6_7.html Acesso em: 26 de jun de 2018

Villa-Valdés, A. 2000. Saunas Castreñas en Astúrias. In: Ochoa, C. F.; Garcia Entero, V. (Eds.) Termas romanas en el Occidente del Imperio, II Coloquio Internacional. Gijón: 97-114.

Disponivel em:

http://www.castrosdeasturias.es/descargas/691-villavaldes-2000.-saunas-castreas.-congreso-gijon.pdf Acesso em: 15 jun 2018

Villa-Valdés, A. 2012. Santuários "urbanos" en la protohistoria cantábrica: algunas consideraciones sobre El significado y función de las saunas castreñas. Boletin del Real Instituto de Estudios Asturianos n.177. Oviedo: 9-46.

Disponível em:

http://www.castrosdeasturias.es/ descargas/830villa-valdes-a.-2012.-santuarios-protohistoricos.pdf Acesso em 16 jun 2018 